\title{
Forging a Research Pathway: Perspectives of Two Post-Tenure Female Faculty Members
}

\author{
Laureen J. McIntyre and Laurie-Ann M. Hellsten
}

University of Saskatchewan

\begin{abstract}
This paper presents an auto-ethnographic exploration of two post-tenure female faculty member's experiences developing their programs of research. Self-reflection was used to explore the factors that have helped or hindered the development of their research program, and the continued challenges they faced as female faculty. Composite themes were generated, using resiliency theory as the framework for discussions. Results are discussed with reference to a multidimensional conceptual model of researcher development put forth by Evans (2011).
\end{abstract}

Key Words: female academics; research program; autoethnography; resilience

Dr. Laureen J. McIntyre is an Associate Professor in the Department of Educational Psychology and Special Education at the University of Saskatchewan. Her research interests relate to how individuals with varied language and learning abilities are having their literacy needs met (i.e., teacher education, knowledge, and practice relating to special education; early intervention; professional mentorship).

Email laureen.mcintyre@usask.ca

Dr. Laurie-Ann Hellsten is an Associate Professor in the Department of Educational Psychology and Special Education at the University of Saskatchewan. Her research interests include instrument development, analysis and validation, program evaluation, and the application of modern quantitative and analytical techniques within the domains of education, health, and health promotion.

Email laurie.hellsten@usask.ca

Brock Education, 24(1), Fall 2014, pp. 55-64 


\section{Introduction}

Research has shown the academic workplace, and the need to achieve tenure within the first six years, is designed in ways that work against women (e.g., Halpern, 2008; Park, 1996; Schultz, 2008). For example, factors contributing to difficulties for women in academic settings include networking that excludes women and work-family conflicts (Bassett, 2005; Foster et al., 2000). In addition, despite idealistic expectations (Rice, Sorcinelli, \& Austin, 2000), faculty report unbalanced lives and feelings of loneliness, isolation, and rivalry between colleagues (Greene et al., 2008). Novice faculty also report becoming dissatisfied, overworked, stressed, and physically ill (Hellsten, Martin, \& McIntyre, 2010; Hellsten, McIntyre, Martin, \& Kinzel, 2011; Hill, 2004), as they attempt to meet the often unwieldy, vague, and increasing tenure and promotion requirements (Schuster \& Finklestein, 2006). The resulting gender disparities (e.g., salary, merit pay) only grow when universities place more emphasis on research relative to teaching and service (Mason \& Goulden, 2002). However, despite a growing body of literature examining the scholarship of researcher development (Evans, 2011), there is no peer reviewed research literature exploring the challenges female academics experience when working to establish a program of research in today's academic environment. In order to address the existing shortfalls in academic institutions, we must first attempt to understand the challenges facing female academics as they work to establish a program of research and generate possible solutions to address these problems. It is important for novice faculty members to share their challenges and tribulations since it can be "therapeutic, healing, and affirming" (Kawalilak \& Groen, 2010, p. 6).

As post-tenure female faculty members, we have endeavoured to share some of our experiences in navigating the university work environment. In our first article, we presented an autoethnographic exploration of three women's experiences of the journey to tenure. Individual stories and composite themes were generated through reflexive writing and focused conversations about our experiences as women navigating the challenges and rewards of the tenure and promotion process (Hellsten et al., 2010). In our second article, we expanded our autoethnographic exploration to create a composite story of experiences and included the reflections of a new faculty member. Using a resiliency frameworkmaking positive adaptations in spite of serious threats or significant adversity to adaptation or development (Masten, 2001), we asked ourselves what factors in our lives have made it possible for us to navigate our tenure track journeys (Hellsten et al., 2011). One aspect of the tenure and promotion journey that can challenge faculty is developing and pursuing a program of research. We now wish to move our investigations to focus specifically on our research journeys. Reflecting on the factors that have helped or hindered the development of our research program, and the continued challenges we face as female faculty, will provide us the opportunity to build a case to improve the academic climate for current and future female faculty.

\section{Methodology}

We conducted an autoethnographic exploration of our research pathways as post-tenure females in university faculty positions. Authoethnography is a form of narrative inquiry legitimatizing the researcher's use of her own experience and requires the researcher write herself into the account of a phenomenon. The defining feature of autoethnography is that it emphasizes subjectivity and requires the researcher to perform a narrative analysis pertaining to herself and intimately related to a particular social phenomenon. Therefore, the written outcomes are as individual as its authors, taking a variety of 
different forms (Ellis, 1999). However, regardless of written form, the authoethnographic representation conveys meaning attached to an experience. The goal of authoethnography is "...to tell a story that readers can enter and feel a part of" (Ellis, 1999, p. 674). We used self-reflection to explore the factors that have helped or hindered the development of our research program, and the continued challenges we face as female faculty.

Our discussions were digitally recorded and transcribed. Following the work of Braun and Clarke (2006), thematic analysis of the interview transcripts was conducted by the researchers. Resiliency theory formed the framework for our discussions on the factors that have helped or hindered the development of our research program, and the continued challenges we face as female faculty. Resiliency is defined as the ability to make positive adaptations in spite of serious threats or significant adversity to adaptation or development (Masten, 2001). Resilience results from the operation of basic human adaptational systems including attachment, extended families, mastery motivation, and selfregulation (Masten, 2001). Development in the face of adversity is robust when these basic systems are functioning. Conversely, when these systems are weakened, the risk for developing problems is much greater. Using the resiliency framework, we can ask ourselves what factors have helped or hindered the development of our research program (e.g., how were you supported by college/faculty to initiate and focus your research program? what factors have helped/hindered you from engaging in your research endeavours?). Resiliency theory is appropriate to use to frame our discussions since it fits in with the perspective of promoting well-being and considering solutions to adversities rather than focusing on hardships and negative experiences. This framework allowed us to consider strategies we have used, or factors that have supported us, in successfully developing our programs of research.

Our reflections on the factors that have helped or hindered the development of our research program, and the continued challenges we face as female faculty, can help to inform others of possible solutions for improving the research journeys for female academics.

\section{Our Research Journeys Context}

We are two female University post-tenured faculty members, hired within the past ten years, who are both currently Associate Professors at the University of Saskatchewan (U of S). Each of us brings different academic/professional experiences (hired without completed doctoral degree and with/without considerable professional experience, including professional licensure), areas of expertise (psychometrician, speech-language pathologist), work experiences (post-doctoral position, previous professional career), family situations (married/single, no/young children), and personal challenges to the process of acquiring tenure/promotion and developing a viable research program. When we started in our tenure track positions, there was no formal or informal research mentorship in our department or college. In addition, a high turnover of faculty members in the role of the department head in the early years of our careers contributed to a lack of consistent research mentorship in our department. We both had limited publishing and grant writing experience coming out of our doctoral training. Although we were both passionate about and had an interest in research, we were left to figure out how to focus and implement our research visions on our own. 


\section{Limited Institutional Support}

In our discussions, we first considered how we were supported by college/faculty to initiate and focus our research programs. One theme emerging from these discussions was that our feelings of isolation, stress, and frustration were due to the limited institutional support initially available to develop our research programs. In comparison to the current environment where every new faculty member at the $U$ of $\mathrm{S}$ is provided with the opportunity to take part in a personalized new Faculty Research mentorship program (University of Saskatchewan, n.d. a), our department and college did not have any type of formal supports in place to help new faculty with their research programs when we started as academics ten years ago (e.g., formal mentorship program). We were left to create our own informal support systems (e.g., partnering with other early career colleagues, seeking out our own research mentors). The mentorship program now in place at the U of S helps new faculty to better understand research culture and the expectations of the university, assists faculty with the development of their research vision/plan and subsequently, through the establishment of milestones, helps the new researcher to develop a timeline for how the research plan will be realized and sustained (University of Saskatchewan, n.d. a). In contrast, we had to take our interest and enthusiasm for research and figure out how to first articulate what we wanted to focus on in our research programs and then decide how to make it a reality.

Laureen: Grants? I had applied for research funding as a doctoral student, but my doctoral supervisor had supported me through that process. Starting as an Assistant Professor here, there was no one more senior to help. I had to talk to colleagues in the same position and figure it out myself by trial and error. And in the beginning it was mostly error. And figuring out how to focus my ideas into a viable research program? I'm still tweaking and refining my area of focus ten years later. It would have a much easier process if a more knowing faculty member or research officer were there to help me along.

Laurie: It was a challenge to formulate independently, our research plans. The idea of having a master plan for my research would have been so incredibly helpful. In the beginning, I heard the message loud and clear that I should pursue external research funding. I jumped on that and began chasing the money. I seriously considered every opportunity that came my way and rarely turned anything down. Although I have been successful and I can articulate how the different projects I have been involved in relate, looking back, I certainly took the road less travelled. It would have been nice to have someone remind me to consider whether a particular opportunity was the right one for me, at that point in my career. Having someone experienced to provide me with the support to turn down an opportunity would have really helped me.

These early career experiences shaped the way our research programs have, and have not, developed. We both have not maintained as focused a program of research as we had originally envisioned. Although we are both satisfied with our current programs of research, we definitely feel there were drawbacks from having to learn as we went along.

Now further into our academic careers, the academic context around us seems to be shifting yet again. Budget cuts and tenure-track faculty positions not being replaced after faculty retire, thereby increasing administrative, teaching, and research expectations, are all negatively influencing our health and well-being as female faculty members working in today's academic institutions. 
Laureen: Our workload seems to be increasing in recent months. So much for finding a better work-life balance following tenure. We have faculty members retiring in our department, yet they aren't being replaced. Someone still has to do their work, that doesn't seem to disappear. There are still committees we need to have representation on, I still need to teach my never decreasing number of assigned classes, and somehow I still have to find time to work on my ongoing research projects and apply for new research funding. I'm stressed, I'm tired, but I don't have time to take a break.

Furthermore, the external research environment is becoming increasingly competitive. There are many more applications being submitted for funding now, but fewer researchers are being funded. In addition, there is an associated pressure to increase publication productivity and impact in order to compete against other researchers.

Laurie: There never seems to be enough time to do all that I want to with respect to research. I seem to have mastered (maybe through experience) the research funding cycle - my submissions are not always funded but I regularly submit quality applications. It's the other research related work - especially writing manuscripts where I seem to experience more challenge. Finding the time to write has been difficult for me. I love the deadlines imposed by grants, and I meet those. But I consistently ignore self-imposed manuscript preparation deadlines. My list of manuscripts in progress never seems to decrease.

The new realities in academia are not lessening the workload for academics.

\section{Factors Hindering or Helping Our Research}

Second, we considered the factors that have hindered and helped our engagement in research endeavours. Three main themes emerged in our discussions of factors that have hindered or helped our research engagement: (1) having to seek out research resources and mentors on our own; (2) having difficulty finding reciprocally supportive research partners; and (3) needing to take advantage of research resources as they became available. Let's first consider having to seek out research resources and mentors on our own, a factor that hindered our engagement in research activities.

Laurie: We were left to seek out our own research mentors to help us both define and narrow our program of research, and formulate a plan of how to best develop this research plan. We had several new or newer faculty around me - this was both helpful and posed challenges. Often I didn't know the right questions to ask or where to look for support, and my colleagues were often in competition with myself for the same grants. So with a lack of transparency regarding what sources of funding were available, I often found out about funding opportunities too late.

Figuring out our next course of action to move our research programs forward was challenging.

Laureen: I knew what I wanted to focus on, but how do you concisely present that to others? Other than tri-agency research funding, where do you go to figure out what other grants and 
funds are available to apply for? And when you do find grants to apply to, when do you have time to do it when you have teaching and administrative obligations you have to meet. I don't know about you, but I like to be able to sleep for more than three hours a night. There aren't enough hours in the day to do all of this and not be a worn out mess.

Reaching out and finding other researchers to work with could help further a person's program of research. The external funding agencies also appear to be placing increasing value on collaboration with the development of additional collaborative funding programs (i.e., partnership grants). However, finding reliable, trustworthy research partners who are collegial has been a factor that hindered our research engagement

Laureen: I've had a few bad experiences trying to make connections with other faculty members to establish my program of research. Not everyone is collegial or willing to live up to agreements that have been made to do the research together and publish. So all the time I've invested to move these projects forward don't benefit me or my research program. It makes you hesitant to engage in new research relationships when you are just waiting for someone to take advantage of you. Through this process I eventually found a research partner I could trust.

It was left up to us as junior faculty members to find someone to navigate us through the research process.

Laurie: I was able to find internal funds, but I wasn't able to use the money as effectively as I would have liked because a structure or a plan was not in place. I found a faculty member in another college who became my research mentor. I worked to build research relationships across campus, which lead to lots of grant writing, but in hindsight these projects were not always with the strongest of co-applicants. I was too busy to take the time to be selective in whom I was working with... Looking back I wonder if they were taking advantage of my knowledge and abilities. And I eventually saw myself starting to help them more than they helped me. Not all working relationships were beneficial to establishing our program of research.

One factor that has helped us further our research endeavours in recent years, is taking advantage of research resources as they became available. Our college recently hired research facilitators to support and enhance the research programs and activities of all university faculty members. Specifically, "research facilitation promotes and supports research activities at the University of Saskatchewan through a network of skilled professionals who help researchers, colleges/schools, and the institution obtain funding and resources, build profiles, and develop research partnerships and collaborations" (University of Saskatchewan, n.d. b, para. 3). Faculty members could use this support to help foster their research programs.

Laureen: I was skeptical when I heard the college was going to hire research facilitators to help us to establish and further, our programs of research. I had been doing it on my own for so long I was less willing to ask for help. When I did go see them, I found their help to be extremely valuable. They not only helped me refine my program of research description, they also helped me find new grants to apply to and spent time editing my grant submissions. I was initially reluctant to ask for 
help, but benefitted when I got over my fears and did seek them out. Taking the time to access new supports has benefited our research.

Laurie: Now I can't imagine my research life without our research facilitators. Even though I have experience applying for external funding, the agencies are always changing the funding programs and increasing the complexity of the programs. It's been a relief to hand-over that work to someone else. Now I can focus on applying for funding or doing the research rather than keeping up to date on all the nuances and changes. The facilitator takes on the task of locating funding opportunities, and I receive reminders of upcoming deadlines. All of this I used to have to do myself. The facilitators also act as a sounding board and it is nice to be able to double check things with them rather than having to do it all on my own.

Making use of the research supports offered by our university has strengthened our research programs and made us more confident in pursuing our research endeavours. As the external research environment becomes increasingly competitive, the supports we have taken advantage of have allowed us to continue to be successful.

\section{Lessons Learned on Our Research Journey}

In reflecting on our research journeys, we noted that many of the changes we, as academics and developing researchers, experienced demonstrated our abilities to make positive adaptations and succeed in spite of adverse circumstances (Masten, 2001). In addition, many of our changes also fit the multidimensional conceptual model of researcher development put forth by Evans (2011). We certainly experienced behavioural development where we changed for the better the way we did research (termed processual change). We learned to play the research game and decipher the institutional research requirements or procedural change (Evans, 2011). We also increased our research output (termed productive change), and became more competent researchers (termed competential change). In addition, we also experienced change in our attitudes and perceptions towards research as we developed our identities as researchers (termed perceptual change) and experienced changes to our base levels of motivation for research or motivational change (Evans, 2011).

What we may not have expected was the degree of change we experienced with respect to what research-related values were important to us (evaluative change). Looking back, neither of us would have predicted how important collaborative relationships would be to our research programs, and the dangers in not pursuing research with like-minded colleagues (e.g., failed relationships, projects not furthering our program of research). Although collaborative research relationships are important, it takes time to build trust. In an ideal world, every researcher would be collegial. In reality, you need to consider your best interests first but do not work to impede others' productivity in the process.

We also experienced intellectual development in our journeys. We changed (for the better) what we know and understand about research (epistemological, rationalistic, comprehensive, and analytical changes). We believe it is important to consider your program of research as a work in progress (i.e., an evergreen plan) and to take advantage of opportunities that expand your focus with colleagues you trust. You will need to modify and refine your research program as you make connections with other researchers. 
Research has been identified as the "single most important area in which individuals and groups need advice in the current academy, and where advice is most singularly lacking" (Delamont \& Atkinson, 2004, p. 2). Thus, we recommend academics take advantage of any and all research resources as they became available to build capacity as a researcher. In order to stay competitive in the current external funding environment, researchers should commit to professional self-development throughout their career (Evans, 2009). As Evans (2011) stated, researcher development is not just about increasing external funding success rates or developing skills. Researcher development is also very much about changing attitudes and perceptions about research. The risk of institutions not providing sufficient support for research is a disengaged tenured academic who underperforms or does not contribute to research productivity or impact. Receiving support from your academic institution, and establishing trustworthy and supportive, collegial relationships can help to forge an academic's research pathway. 


\section{References}

Bassett, R. H. (Ed.). (2005). Parenting and professing: Balancing family work with an academic career. Nashville: Vanderbilt University Press.

Braun, V., \& Clarke, V. (2006). Using thematic analysis in psychology. Qualitative Research in Psychology, 3, 77-101.

Delamont, S. \& Atkinson, P. (2004). Successful Research Careers: A Practical Guide, Society for Research into Higher Education \& Open University Press, Maidenhead.

Ellis, C. (1999). Heartful autoethnography. Qualitative Health Researcher, 9(5), 653-667.

Evans, L. (2009). Developing research capacity in the social sciences: a professionality based model, International Journal for Researcher Development, 1 (2), 134-149.

Evans, L. (2011). The scholarship of researcher development: mapping the terrain and pushing back boundaries. International Journal for Researcher Development, 2 (2), 75-98.

Foster, S.W., McMurray, J.E., Linzer, M., Leavitt, J. W., Rosenberg, M., \& Carnes, M. (2000). Results of a gender-climate and work- environment survey at a Midwestern academic health centre. Academic Medicine, 75, 653-660.

Greene, H.C., O' Connor, K.A., Good, A.J., Ledford, C.C., Peel, B.D., \& Zhang, G. (2008). Building a support system toward tenure: Challenges and needs of tenure-track faculty in colleges of education. Mentoring \& Tutoring: Partnership in Learning, 16(4), 429-447.

Halpern, D.F. (2008). Nurturing careers in psychology: Combining work and family. Educational Psychological Review, 20, 57-64.

Hellsten, L.M., Martin, S., \& McIntyre, L.J. (2010). Navigating the pot holes and speed bumps: Three female perspectives on tenure. Journal of Educational Thought, 44(1), 99-115.

Hellsten, L., McIntyre, L.J., Martin, S., \& Kinzel, A. (2011). Women on the academic tenure track: An autoethnographic inquiry. International Journal for Cross-Disciplinary Subjects in Education, 2(1), 271-275.

Hill, N. R. (2004). The challenges experienced by pretenured faculty members in counselor education: A wellness perspective. Counselor Education and Supervision, 44(2), 135.

Kawalilak, C., \& Groen, J. (2010). Perspectives - The road to tenure. Journal of Educational Thought, 44(1), 2010, pp. 5-9.

Mason, M.A., \& Goulden, M. (2002). Do babies matter? The effect of family formation on the lifelong careers of academic men and women. Academe, 88(6), 21-27.

Masten, A.S. (2001). Ordinary magic: Resilience processes in development. American Psychologist, 56, 227-238.

Park, S. M. (1996). Research, teaching, and service: Why shouldn't women's work count? Journal of Higher Education, 67, 46-84. 
University of Saskatchewan (n.d. a). Research Mentorship Program. Retrieved November 1, 2014 from http://research.usask.ca/for-researchers/index.php

University of Saskatchewan. (n.d. b). Research Facilitation. Retrieved November 1, 2014 from http://library.usask.ca/ceblip/research/research-facilitation.php.

Rice, R., Sorcinelli, M., \& Austin, K. (2000). Heeding New Voices: Academic Careers for a New Generation. American Association for Higher Education, Washington, DC.

Schultz, N. (2008). Balancing faculty careers and family work: Tenure-track women's perceptions of and experiences with work/family issues and their relationships to job satisfaction. Paper presented at the 94th Annual Convention of the NCA, San Diego, CA. Retrieved September 30, 2009 from www.allacademic.com/meta/p259816_index.html

Schuster, J., \& Finklestein, M. (2006). The American Faculty: The Restructuring of Academic Work and Careers. Johns Hopkins University Press, Baltimore, MD. 